\title{
Use, Persistence, Efficacy, and Safety of Apixaban in Patients with Non-Valvular Atrial Fibrillation in Unselected Patients in Germany. Results of the Prospective Apixaban in Atrial Fibrillation (APAF) Registry
}

Uwe Zeymer · Christiane Lober · Andreas Wolf · Frank Richard ·

Heinrich Schäfer · Jens Taggeselle · Hans-Joachim Kabitz •

Roland Prondzinsky · Tim Süselbeck on behalf of the APAF-Investigators

Received: April 27, 2020 / Published online: July 8, 2020

(C) The Author(s) 2020

\section{ABSTRACT}

Introduction: Apixaban has been shown to be superior to warfarin in patients with nonvalvular atrial fibrillation in the randomized ARISTOTLE trial and its use is recommended in current guidelines. There are only scarce data about its use, efficacy, and safety in unselected patients in Germany.

Methods and Results: The APAF registry is a prospective non-interventional study enrolling

Digital Features To view digital features for this article go to https://doi.org/10.6084/m9.figshare.12514343.

Electronic supplementary material The online version of this article (https://doi.org/10.1007/s40119020-00188-1) contains supplementary material, which is available to authorized users.

\section{U. Zeymer $(\bowtie)$}

Klinikum Ludwigshafen, Ludwigshafen, Germany

e-mail: uwe.zeymer@t-online.de

U. Zeymer · C. Lober

Institut für Herzinfarktforschung Ludwigshafen, Ludwigshafen, Germany

A. Wolf

Kardiologische Praxis, Stahnsdorf, Germany

F. Richard

Praxis Dr. Richard, Erfurt, Germany

H. Schäfer

Praxis Dr. Schäfer, Herfurth, Germany
5015 patients with non-valvular atrial fibrillation. Of these, 1349 (26.9\%) patients were initially treated with apixaban and followed up at 3 and 12 months. The dose of apixaban used was $1 \times 2.5 \mathrm{mg}$ in $1.6 \%, 2 \times 2.5 \mathrm{mg}$ in $30.4 \%$, and $2 \times 5 \mathrm{mg}$ daily in $68.0 \%$ of patients, respectively. Inappropriate underdosing of apixaban was observed in $22.3 \%$, mostly in elderly patients with higher HAS-BLED Score and a history of bleeding. Persistence to apixaban after 1 year was $88.6 \%$, while the dose was changed in $3.7 \%$ of patients. Switching to other NOACs or VKAs occurred in $5.1 \%$. After 12 months, all-cause mortality was $5.0 \%$, nonfatal stroke occurred in $0.4 \%$, non-fatal myocardial infarction in $0.6 \%$, ISTH major bleeding in $0.8 \%$, moderate or minor bleeding in $4.3 \%$ of patients, respectively.

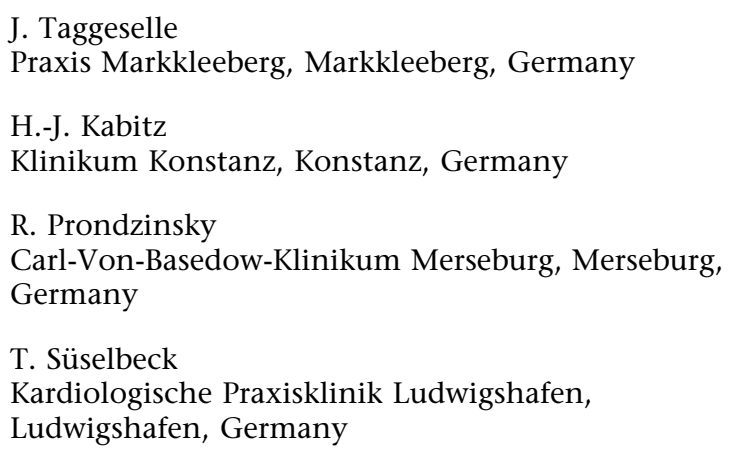


Conclusions: In this prospective experience in unselected patients with atrial fibrillation, persistence to apixaban was high, and efficacy and safety were comparable to the results in clinical trials, supporting its use in clinical practice.

Keywords: Atrial fibrillation; Apixaban; Prospective registry; Persistence

\section{Key Summary Points}

Why carry out this study?

Little is known about the persistence, efficacy, and safety of apixaban in patients with atrial fibrillation in real life.

This study prospectively studied adherence, reasons for discontinuation, and events of patients with atrial fibrillation that were prescribed apixaban.

\section{What was learned from the study?}

A total of 1349 patients were treated with apixaban and followed up at 3 and 12 months. Inappropriate underdosing of apixaban was observed in $22.3 \%$, mostly in elderly patients with higher HAS-BLED Score and a history of bleeding. Persistence to apixaban after 1 year was $88.6 \%$. Switching to other NOACs or VKAs occurred in $5.1 \%$. After 12 months allcause mortality was $5.0 \%$, non-fatal stroke occurred in $0.4 \%$, non-fatal myocardial infarction in $0.6 \%$, ISTH major bleeding in $0.8 \%$, moderate or minor bleeding in $4.3 \%$ of patients, respectively.

Therefore the results from the randomized trials with apixaban can be translated to its performance in real life.

\section{INTRODUCTION}

Apixaban is an oral factor Xa inhibitor [1], which has been tested [2,3] and approved for the prevention of systemic embolism or stroke in non-valvular atrial fibrillation. In the large ARISTOTLE phase 3 study, apixaban was superior to warfarin. It reduced the primary endpoint of stroke or systemic embolism, caused less bleeding, and reduced all-cause mortality [3]. Subsequently, apixaban has been approved by the European Medicines Agency for use in patients with atrial fibrillation and is recommended in the current guidelines of the European Society of Cardiology [4, 5]. Previous reports about real-world experience of apixaban derive mostly from retrospective analyses of insurance and claims data [6-8], which is associated with a number of limitations. It is therefore of scientific interest to assess the use of apixaban in daily practice with respect to patient selection, persistence of therapy, and midterm embolic and bleeding events in a prospective manner. Therefore, we conducted a prospective study with the use of apixaban in patients with atrial fibrillation in a real-world setting.

\section{METHODS}

The APixaban in Atrial Fibrillation (APAF) Registry was a prospective non-interventional, multicenter study in consecutive patients with non-valvular atrial fibrillation. The registry was an observational study and patient's participation in this study had no impact on his or her indication for treatment, diagnostics, or therapy. Subjects were supposed to be treated according to current international and national guidelines and the site's internal guidelines. Treatment patterns and treatment initiation, continuation, or changes were solely at the discretion of the physician and the patient. All drug subscriptions applied were in the usual standard of care. Participation in the registry did in no way influence payment or reimbursement for any treatment received by subjects during the study. The registry has been registered under ClinicalTrials.gov identifier number NCT 02563639 . 


\section{Patients}

Inclusion criteria were age $>18$ years, nonvalvular atrial fibrillation, and written informed consent. The only exclusion criterium was participation in any randomized trial. The planned sample size of 5000 guaranteed that the proportion of interesting subgroups (for example, patients treated not according the current guidelines) representing $10 \%$ of register population could be estimated with a precision (halfwidth of a $95 \% \mathrm{CI}$ ) of $1 \%$ or better. For all patients treated with apixaban at baseline, a long-term follow-up was performed for at least 12 months. The follow-ups of patients treated with apixaban were performed centrally using a standardized patient interview (telephone call) at 3 and 12 months. In case of embolic, ischemic bleeding, or any other adverse events, the treating physician was asked for a patient chart for verification. If the patient was not accessible by phone, local registration offices were contacted for further information.

\section{Quality Control}

Thirty on-site monitoring visits were performed at 30 sites. Fifteen sites were selected randomly, while 15 other sites were selected based on remote data checks, enrolment rates, and other reasons. During on-site monitoring, the following details were checked for accuracy, completeness, and consistency: investigator site file for completeness, patient informed consent of all patients at site, protocol violations, source data verification of five patients per site, AE/SAE reporting, and follow-up. Monitoring reports were written after each visit and sent to the site to resolve open issues. Overall, all open issues were resolved; no site was excluded from the study.

\section{Ethics Compliance}

The registry has been approved by the ethics' committee of Landesärztekammer RheinlandPfalz and the ethic committees of the participating centers.
The study was initially reviewed by an Independent Ethics Committee (IEC). A favorable opinion was provided by the ethics committee (Ethik-Kommission der Landesär ztekammer Rheinland-Pfalz) on 28-AUG-2015, No. 837.279.15 [10,047].

The following ethics committees were additionally involved (with date of IEC favorable opinion): EK Schleswig-Holstein (19.10.201), EK Hessen (22.10.2015), EK Niedersachsen (26.10.2015), EK Uni Lübeck (02.11.2015), EK Thüringen (03.11.2015), EK Brandenburg (10.11.2015), EK Sachsen (11.11.2015), EK Uni Rostock (11.11.2015), EK Baden-Württemberg (01.12.2015), EK Sachsen-Anhalt (02.12.2015), EK Uni Greifswald (02.12.2015), EK Saarland (08.12.2015), EK Hamburg (11.12.2015), EK Nordrhein (30.12.2015), EK Westfalen-Lippe (14.01.2016), EK Bremen (01.03.2016), EK Uni Heidelberg (28.04.2016), EK Uni Mannheim (17.06.2016), EK Uni Düsseldorf (22.06.2016), EK Erlangen (26.07.2016), EK Uni Dresden (28.07.2016), EK Uni Tübingen (15.09.2016), K Charité Berlin (28.10.2016).

The initial favorable opinion of the EthikKommission der Landesärztekammer Rheinland-Pfalz was accepted by the following IECs without the need to submit the study additionally: EK Berlin and EK Bayern.

After receiving a favorable opinion, patient enrolment could be initiated. Every patient participating in the study had to sign an informed consent form allowing data processing.

The study was conducted in accordance with the ethical principles that have their origins in the Declaration of Helsinki.

The patients' privacy was kept according to the requirements of Directive 95/46 EC and national legislation for data protection. Data were collected in a pseudonymous way. An identification number assigned to each patient was used in lieu of the patient's name to protect the patient's identity when reporting registryrelated data. 


\section{Definitions}

Major bleeding was defined according to the ISTH definition [9]. All other bleedings were classified as moderate or minor bleedings. Stroke was defined as an acute new neurological deficit ending in death or lasting longer than $24 \mathrm{~h}$, and classified by a physician as a stroke. Stroke was classified as hemorrhagic (cranial CT, MRI, or autopsy) or non-hemorrhagic. Persistence was defined as the duration of time from baseline to discontinuation of apixaban.

\section{Statistics}

The statistical analysis of the APAF Registry was of exploratory nature. A biometrical report including descriptive statistics of all documented parameters was generated. Due to the exploratory nature of the survey, formal statistical tests were not performed. Binary, categorical, and ordinal parameters were described using absolute numbers and percentages, continuous/numerical variables by means of standard statistics (i.e., mean, standard deviation, minimum, median, maximum, lower, and upper quartile). For exploratory purposes, logistic regression analyses were conducted to identify independent predictors of the use of apixaban or the discontinuation of apixaban.

\section{RESULTS}

During the enrolment period from September 2015 to January 2017, a total of 102 hospitals and specialized and non-specialized office-based centers in Germany enrolled patients. Ultimately, 5015 patients were included in the study. Among those, 1349 (26.9\%) patients were treated with apixaban and prospectively followed up at 3 and 12 months. The baseline characteristics of patients treated with apixaban and without apixaban are given in Table 1 . The non-apixaban patients were treated without antithrombotic therapy in $3.7 \%$, with a platelet inhibitor in $3.1 \%$, with a vitamin $\mathrm{K}$ antagonist in $31.6 \%$, with dabigatran in $6.5 \%$, with edoxaban in $6.5 \%$ and with rivaroxaban in $23.7 \%$.
The mean age of the patients was 74.2 years, while the majority of patients were 75 years of age or older $(57.3 \%)$ and $44 \%$ of the patients were female. In Table 2, independent factors for the use of apixaban are given, which included prior stroke and heart failure, while the other factors did not influence the use of apixaban.

The dose of apixaban used was $1 \times 2.5 \mathrm{mg}$ in $1.6 \%, 2 \times 2.5 \mathrm{mg}$ in $30.4 \%$, and $2 \times 5 \mathrm{mg}$ daily in $68.0 \%$ of patients, respectively. Based on the label (two of three factors present: age $\geq 80$ years, creatinine $\geq 1.5 \mathrm{mg} / \mathrm{dl}$, body weight $\leq 60 \mathrm{~kg}$, or GFR $15-29 \mathrm{ml} / \mathrm{min}$ or a GFR of $15-29 \mathrm{ml} / \mathrm{min}$ ) an indication for the reduced dose of $2 \times 2.5 \mathrm{mg}$ was present in $10.2 \%$ of the patients treated with apixaban. Important baseline characteristics of the 301 patients $(22.3 \%)$ with a reduced dose of apixaban not indicated by the label are shown in Table 3 . Additional antiplatelet therapy was given in $5.4 \%$ of the apixaban patients, with dual antiplatelet therapy reported in $1.7 \%$.

A prospective 3- and 12-month follow-up was performed in 1337 (99.1\%) and 1279 (94.8\%) patients of the 1349 patients initially treated with apixaban, respectively. The persistence to apixaban during the 12-month followup was $88.6 \%$. Figure 1 depicts the cumulative rate of patients with continuous treatment with apixaban during follow-up. Apixaban was discontinued by the patient himself in $4.0 \%(5 /$ 126), by the general practitioner in $31.0 \%$ (39/ $126)$, by the treating cardiologist in $37.3 \%$ (47/ $126)$, and by hospitals in $27.8 \%(35 / 126)$. Reasons for apixaban discontinuation were as follows: bleeding in $8.0 \%(10 / 126)$, falls in $2.4 \%$ $(3 / 126)$, surgery in $8.0 \%(10 / 126)$, return to sinus rhythm in $13.6 \%(17 / 126)$, side effects in $12.8 \%(16 / 126)$, other concomitant diseases in $3.2 \%(4 / 126)$, and for other reasons and unspecified in $61.6 \%(77 / 126)$. We could not identify independent predictors for discontinuation of apixaban in the multivariate regression analysis. Apixaban therapy was interrupted in $3.3 \%$ of patients, with one interruption in $78.6 \%$, two interruptions in $16.7 \%$, and more than two interruptions in $4.8 \%$ of the latter, respectively. A change in the dose of apixaban during the 12-month follow-up was reported in $3.7 \%$ of patients. At 12 -month follow-up, $2.0 \%$ 
Table 1 Baseline characteristics of patients with atrial fibrillation treated with and without apixaban

\begin{tabular}{|c|c|c|c|}
\hline & Apixaban $(n=1349)$ & No apixaban $(n=3666)$ & $p$ value \\
\hline Mean age (years) & 73.9 & 74.3 & 0.2 \\
\hline Age $\geq 75$ years & $54.9 \%$ & $58.1 \%$ & 0.06 \\
\hline Women & $48.0 \%$ & $43.4 \%$ & $<0.01$ \\
\hline Paroxysmal AF & $52.2 \%$ & $43.8 \%$ & $<0.0001$ \\
\hline Persistent AF & $27.2 \%$ & $20.5 \%$ & \\
\hline Permanent AF & $20.7 \%$ & $35.7 \%$ & \\
\hline Prior cardioversion & $30.1 \%$ & $27.6 \%$ & 0.8 \\
\hline Prior pulmonary vein isolation & $7.0 \%$ & $8.5 \%$ & 0.09 \\
\hline Prior left atrial appendage occlusion & $0.4 \%$ & $1.1 \%$ & $<0.05$ \\
\hline Prior pacemaker & $13.2 \%$ & $16.7 \%$ & $<0.01$ \\
\hline Prior ICD and CRT & $4.9 \%$ & $5.0 \%$ & 0.9 \\
\hline Coronary artery disease & $29.7 \%$ & $35.5 \%$ & $<0.01$ \\
\hline Prior myocardial infarction & $10.1 \%$ & $11.7 \%$ & 0.5 \\
\hline Heart failure & $33.0 \%$ & $39.7 \%$ & $<0.001$ \\
\hline Reduced left ventricular function & $39.5 \%$ & $45.5 \%$ & $<0.01$ \\
\hline Prior stroke & $11.5 \%$ & $11.0 \%$ & 0.6 \\
\hline Prior TIA & $5.7 \%$ & $4.6 \%$ & 0.12 \\
\hline Diabetes mellitus & $27.5 \%$ & $30.7 \%$ & $<0.05$ \\
\hline Hypertension & $84.7 \%$ & $87.0 \%$ & $<0.05$ \\
\hline $\mathrm{GFR}<60 \mathrm{ml} / \mathrm{min}$ & $37.3 \%$ & $38.6 \%$ & 0.48 \\
\hline Prior major ISTH bleeding & $1.4 \%$ & $2.5 \%$ & $<0.05$ \\
\hline Prior moderate or minor bleeding & $3.6 \%$ & $3.7 \%$ & 0.8 \\
\hline Mean CHADS-VASc score & 3.76 & 3.89 & $<0.01$ \\
\hline \multicolumn{4}{|l|}{ CHADS-VASc SCore } \\
\hline 0 & $1.6 \%$ & $1.9 \%$ & \\
\hline 1 & $6.2 \%$ & $4.9 \%$ & \\
\hline $2-4$ & $60.9 \%$ & $58.7 \%$ & \\
\hline$>4$ & $31.4 \%$ & $34.5 \%$ & \\
\hline Mean HAS-BLED score & 2.14 & 2.30 & $<0.001$ \\
\hline \multicolumn{4}{|l|}{ HAS-BLED score } \\
\hline $0-1$ & $21.7 \%$ & $16.4 \%$ & \\
\hline 2 & $48.4 \%$ & $46.6 \%$ & \\
\hline$\geq 3$ & $29.9 \%$ & $37.0 \%$ & \\
\hline
\end{tabular}


Table 2 Independent predictors of apixaban treatment in the logistic regression model

\begin{tabular}{lll}
\hline Variable & Odds ratio & 95\% Confidence interval \\
\hline Age & 1.01 & $0.99-1.02$ \\
Male & 0.86 & $0.73-1.01$ \\
Body weight & 0.99 & $0.994-1.003$ \\
$\mathrm{EF}<40 \%$ & 1.06 & $0.95-1.18$ \\
Heart Failure & 0.77 & $0.65-0.91$ \\
GFR $<60 \mathrm{ml} / \mathrm{min}$ & 1.0 & $0.98-1.02$ \\
Diabetes mellitus & 0.96 & $0.81-1.13$ \\
Prior bleeding & 0.84 & $0.49-1.46$ \\
HAS-BLED score & 0.91 & $0.80-1.02$ \\
Prior stroke & 1.29 & $1.01-1.66$ \\
\hline
\end{tabular}

Table 3 Baseline characteristics and 1-year outcomes of patients with adequate and inadequate dosing of apixaban

\begin{tabular}{lllc}
\hline & Adequate dosing $(\boldsymbol{n}=\mathbf{1 0 4 8})$ & Inadequate dosing $(\boldsymbol{n}=\mathbf{3 0 1})$ & $\boldsymbol{p}$ value \\
\hline Mean age & 72.7 years & 77.2 years & $<0.001$ \\
Women & $46.5 \%$ & $52.5 \%$ & 0.06 \\
Mean CHADS-VASc 2 score & 3.6 & 4.1 & $<0.001$ \\
Mean HAS-BLED score & 2.0 & 2.5 & $<0.001$ \\
HAS-BLED score $>3$ & $26.1 \%$ & $46.8 \%$ & $<0.001$ \\
History of severe bleeding & $1.0 \%$ & $2.7 \%$ & 0.06 \\
Severe bleeding under anticoagulation & $0.7 \%$ & $1.7 \%$ & 0.07 \\
History of moderate bleeding & $2.8 \%$ & $6.0 \%$ & $<0.05$ \\
GFR 30-59 & $27.1 \%$ & $53.8 \%$ & $<0.0001$ \\
Additional antiplatelet therapy & $4.5 \%$ & $11.0 \%$ & $<0.001$ \\
1-year outcomes & & & 0.57 \\
Stroke & $0.6 \%$ & $0.3 \%$ & 0.48 \\
Major bleeding & $0.9 \%$ & $1.3 \%$ & 0.31 \\
Death & $4.8 \%$ & $6.3 \%$ & \\
\hline
\end{tabular}

were on $2.5 \mathrm{mg}, 31.8 \%$ on $2 \times 2.5 \mathrm{mg}$, and $66.2 \%$ on $2 \times 5 \mathrm{mg}$ daily, respectively.

Switching to other NOACs (3.6\%) and VKAs $(1.5 \%)$ occurred in $5.1 \%$ of patients.
During the 12-month follow-up, $5 \%$ of the patients died. The rate of stroke or systemic embolism during follow-up is given in Table 4 . ISTH major bleeding complications during 


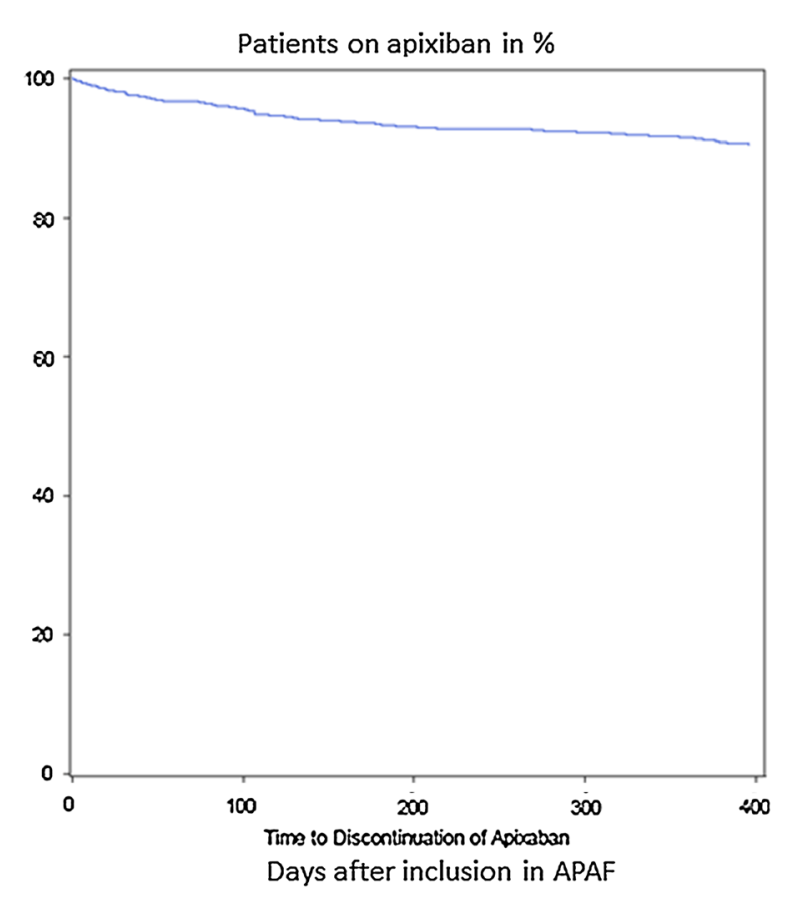

Fig. 1 Persistence to apixaban during follow-up

follow-up were reported in $0.8 \%$ of patients. The rate of cardiac and non-cardiac procedures was high, about one-third of the patients had an invasive procedure (Table 4).

\section{DISCUSSION}

To the best of our knowledge, APAF represents the first nationwide prospective non-interventional study investigating the use, persistence, safety, and efficacy of apixaban in patients with non-valvular atrial fibrillation in a real-life setting in Germany. Apixaban was launched in Germany in November of 2011. In April of 2013, the Federal Joint committee of Germany (GBA = Gemeinsame Bundesausschuß) issued a statement indicating a hint for minor additional benefit of apixaban for the treatment of patients with non-valvular atrial fibrillation [10]. We started our registry in September of 2015 , so that a realistic picture of the use of apixaban in Germany can be expected.

From a total of 5015 patients, about 27\% were treated with apixaban. Independent predictors for and against the use of apixaban included prior stroke (for) and heart failure (against), while all other variables were not related to apixaban use.

One problem of long-term oral anticoagulation is the adherence to this therapy. Previous reports suggest a rapid decline in adherence to oral anticoagulation with vitamin $\mathrm{K}$ antagonists within the first years $[11,12]$. With the advent of the NOACs, higher adherence rates have been reported $[13,14,15]$. A retrospective analysis of primary care data in Germany reports about a persistence to apixaban after 1 year in $62.9 \%$ with apixaban and $57.5 \%$ with VKAs [16]. In the randomized AEGEAN study investigating the effect of an educational program on the adherence and persistence to apixaban therapy, adherence and persistence with apixaban therapy after 48 months was about $90 \%$ and $86 \%$, respectively [17]. This matches favorably with our experience, in which we observed an $88 \%$ persistence to apixaban after 12 months. The fact that patients had to provide informed consent might imply that a positive selection of patients with a better compliance were included into APAF. However, our results suggest that adherence to and persistence of oral anticoagulation with a NOAC seems to be improved in those with VKAs in historic controls $[11,12]$.

Physicians tend to underdose antithrombotic drugs, especially oral anticoagulants because of the fear of bleeding complications. In APAF, about $22 \%$ of patients were treated with a reduced dose of apixaban not recommended by the label. These patients were older, had a higher rate of previous bleedings, and a higher HAS-Bled score. In a single-center experience, $23 \%$ of patients were either under- or overdosed with NOACs [18]. In larger populations, the rate of inappropriate dosing of apixaban ranged between 15 and 20\% [19-21]. The reports about the consequences of inadequate underdosing are conflicting [19-21]. It might very well be that the clinical judgement of the treating physician with respect to appropriate dose of the patient is as good as the recommendations given in the label. In APAF in underdosed patients, we did observe an increase in stroke or mortality.

The overall 1-year mortality in APAF was higher than in the randomized trials [2, 3] 
Table 4 Events and procedures during 12-month follow-up

\begin{tabular}{lll}
\hline Event & $\boldsymbol{n}$ & \% \\
\hline Death & 67 & $5.0 \%$ \\
Cardiovascular death & 10 & $0.7 \%$ \\
Non cardiovascular death & 15 & $0.7 \%$ \\
Unspecified & 42 & $0.7 \%$ \\
Non-fatal myocardial infarction & 8 & $0.6 \%$ \\
Non-fatal stroke or TIA & 6 & $0.4 \%$ \\
Major bleeding & 11 & $0.8 \%$ \\
Moderate or minor bleeding & 58 & $4.3 \%$ \\
Cardiovascular procedures & & $4.0 \%$ \\
Pacemaker implantation & 54 & $5.2 \%$ \\
Cardioversion & 70 & $5.4 \%$ \\
Pulmonary vein isolation & 72 & $0.1 \%$ \\
Interventional left atrial appendage occlusion & 1 & $4.2 \%$ \\
Coronary angiography & 56 & $2.0 \%$ \\
PCI & 27 & $0.2 \%$ \\
CABG & 3 & $0.7 \%$ \\
Heart valve implantation or surgery & 10 & $22.7 \%$ \\
Non-cardiac procedures and surgery & 304 &
\end{tabular}

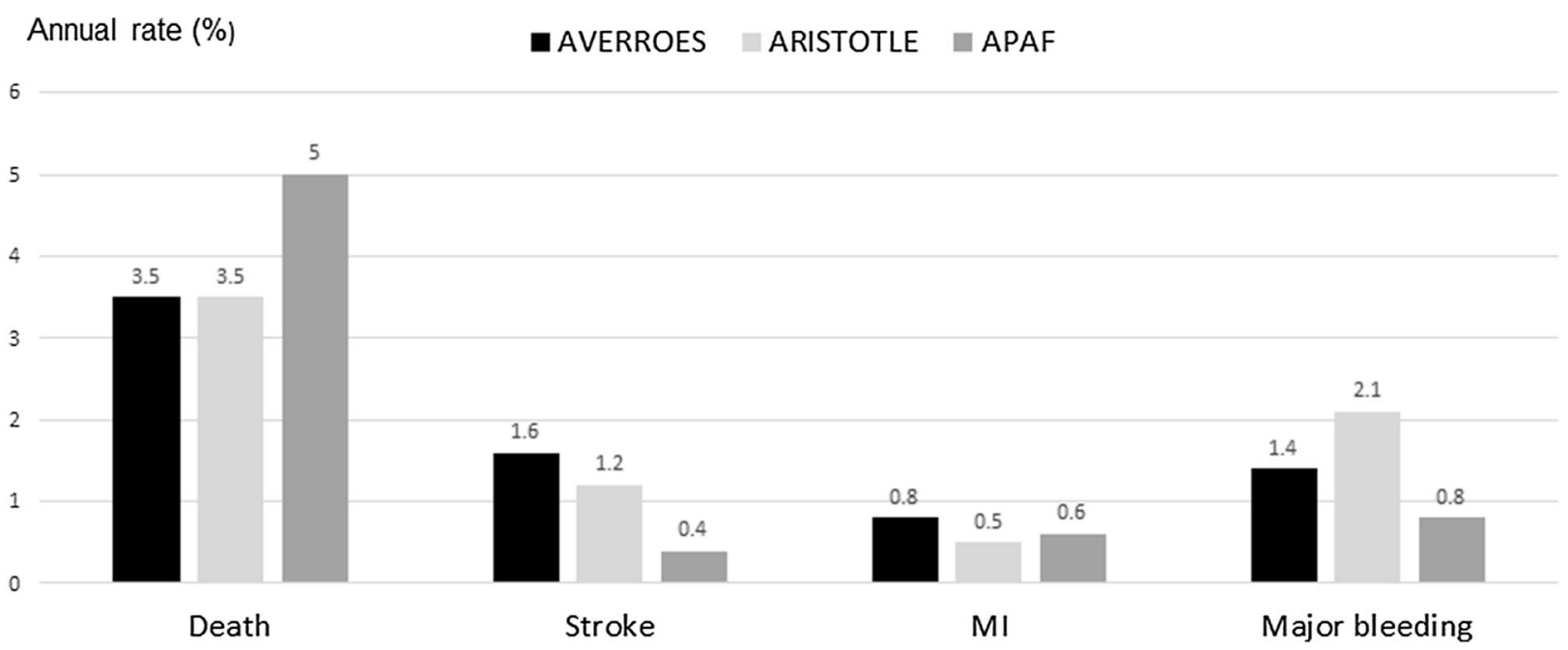

Fig. 2 Annual rates of all-cause mortality, stroke, myocardial infarction, and ISTH major bleeding in AVERROES [2], ARISTOTLE [3], and APAF 
(Fig. 2), possibly reflecting the higher-risk population in APAF. On the other hand, the rates of non-fatal stroke and non-fatal myocardial infarction were lower. It might be possible that we missed a number of fatal strokes and myocardial infarctions because the cause of death was undetermined in two-thirds of the patients.

Recently, two other prospective registries performed in patients with non-valvular atrial fibrillation treated with rivaroxaban [22] and edoxaban [23] have been published. In the XANTUS registry with rivaroxaban, the mean CHADS-VASc score was $3.4 \%$ and in the ETNAAF registry with edoxaban it was 3.1, while we observed a score of 3.8 in the apixaban treated patients. The total mortality rates after 1 year were $1.9 \%$ in XANTUS, $3.6 \%$ in ETNA-AF, and $5.0 \%$ in APAF, and corresponding stroke rates were $0.8,0.8$, and $0.4 \%$, respectively. These results demonstrate that despite comparable patient characteristics, outcomes are different, especially with respect to mortality. This is mainly related to the extent of co-morbidities, which majorly influences total mortality. Therefore, the APAF registry seems to have included a non-selected cohort of patients, representing a "real-world" experience of NOACs. In this context, the low rate of major bleeding in this high-risk population is reassuring.

\section{LIMITATIONS}

We also intended to enroll consecutive patients a selection bias because of the need for informed consent cannot be ruled out. The cause of death could not be determined in twothirds of the patients, leaving the possibility of an underestimation of the total stroke and myocardial infarction rate. In addition, minor and moderate bleeding is often underreported in registries.

\section{CONCLUSIONS}

In this large prospective non-interventional study, adherence to apixaban after 12 months was high, while the reported rates of non-fatal embolic, ischemic, and bleeding events were low. These results are in line with the findings of randomized trials and support the use of apixaban in clinical practice.

\section{ACKNOWLEDGEMENTS}

Funding. This work was supported by an unrestricted grant of Bristol Myers Squibb, Germany. No Rapid Service Fee was received by the journal for the publication of this article.

Authorship. All named authors meet the International Committee of Medical Journal Editors (ICMJE) criteria for authorship for this article, take responsibility for the integrity of the work as a whole, and have given their approval for this version to be published.

Disclosures. Uwe Zeymer has received personal fees from Bayer, Boehringer Ingelheim, BMS, Daichi Sanyo, and Pfizer. Christiane Lober, Andreas Wolf, Frank Richard, Heinrich Schäfer, Jens Taggeselle, Hans-Joachim Kabitz, Roland Prondzinsky, and Tim Süselbeck have nothing to disclose. For a full list of study investigators, please see the supplementary material.

Compliance with Ethics Guidelines. The registry has been approved by the ethics committee of Landesärztekammer Rheinland-Pfalz and the ethic committees of the participating centers. The study was initially reviewed by an Independent Ethics Committee (IEC). The favorable opinion was provided by the ethics committee (Ethik-Kommission der Landesärztekammer Rheinland-Pfalz) on 28-AUG-2015, No. 837.279.15 (10047). The following ethics committees were additionally involved (with date of IEC favorable opinion): EK Schleswig-Holstein (19.10.201), EK Hessen (22.10.2015), EK Niedersachsen (26.10.2015), EK Uni Lübeck (02.11.2015), EK Thüringen (03.11.2015), EK Brandenburg (10.11.2015), EK Sachsen (11.11.2015), EK Uni Rostock (11.11.2015), EK Baden-Württemberg (01.12.2015), EK Sachsen- 
Anhalt (02.12.2015), EK Uni Greifswald (02.12.2015), EK Saarland (08.12.2015), EK Hamburg (11.12.2015), EK Nordrhein (30.12.2015), EK Westfalen-Lippe (14.01.2016), EK Bremen (01.03.2016), EK Uni Heidelberg (28.04.2016), EK Uni Mannheim (17.06.2016), EK Uni Düsseldorf (22.06.2016), EK Erlangen (26.07.2016), EK Uni Dresden (28.07.2016), EK Uni Tübingen (15.09.2016), K Charité Berlin (28.10.2016). The initial favorable opinion of the Ethik-Kommission der Landesärztekammer Rheinland-Pfalz was accepted by the following IECs without the need to submit the study additionally: EK Berlin and EK Bayern. After receiving favorable opinion, patient enrolment could be initiated. Every patient participating in the study had to sign an informed consent form allowing data processing. The study was conducted in accordance with the ethical principles that have their origins in the Declaration of Helsinki. The patients' privacy was kept according to the requirements of Directive 95/46 EC and national legislation for data protection. Data were collected in a pseudonymous way. An identification number assigned to each patient was used in lieu of the patient's name to protect the patient's identity when reporting registry-related data.

Data Availability. The datasets analyzed during the current study are available from the corresponding author on reasonable request.

Open Access. This article is licensed under a Creative Commons Attribution-NonCommercial 4.0 International License, which permits any non-commercial use, sharing, adaptation, distribution and reproduction in any medium or format, as long as you give appropriate credit to the original author(s) and the source, provide a link to the Creative Commons licence, and indicate if changes were made. The images or other third party material in this article are included in the article's Creative Commons licence, unless indicated otherwise in a credit line to the material. If material is not included in the article's Creative Commons licence and your intended use is not permitted by statutory regulation or exceeds the permitted use, you will need to obtain permission directly from the copyright holder. To view a copy of this licence, visit http://creativecommons.org/licenses/by$\mathrm{nc} / 4.0 /$.

\section{REFERENCES}

1. Raghavan $N$, Frost $\mathrm{CE}, \mathrm{Yu} \mathrm{Z}$, He $\mathrm{K}$, Zhang $\mathrm{H}$, Humphreys WG, Pinto D, Chen S, Bonacorsi S, Wong PC, Zhang D. Apixaban metabolism and pharmacokinetics after oral administration to humans. Drug Metab Dispos. 2009;37:74-81.

2. Connolly SJ, Eikelboom J, Joyner C, Diener HC, Hart R, Golitsyn S, Flaker G, Avezum A, Hohnloser SH, Diaz R, Talajic M, Zhu J, Pais P, Budaj A, Parkhomenko A, Jansky P, Commerford P, Tan RS, Sim $\mathrm{KH}$, Lewis BS, Van Mieghem W, Lip GY, Kim JH, Lanas-Zanetti F, Gonzalez-Hermosillo A, Dans AL, Munawar M, O'Donnell M, Lawrence J, Lewis G, Afzal R, Yusuf S. Apixaban in patients with atrial fibrillation. N Engl J Med. 2011;364:806-17.

3. Granger CB, Alexander JH, McMurray JJ, Lopes RD, Hylek EM, Hanna M, Al-Khalidi HR, Ansell J, Atar D, Avezum A, Bahit MC, Diaz R, Easton JD, Ezekowitz JA, Flaker G, Garcia D, Geraldes M, Gersh BJ, Golitsyn S, Goto S, Hermosillo AG, Hohnloser SH, Horowitz J, Mohan P, Jansky P, Lewis BS, LopezSendon JL, Pais P, Parkhomenko A, Verheugt FW, Zhu J, Wallentin L. Apixaban versus warfarin in patients with atrial fibrillation. $\mathrm{N}$ Engl J Med. 2011;365:981-92.

4. Kirchhof P, Benussi S, Kotecha D, Ahlsson A, Atar D, Casadei B, Castella M, Diener HC, Heidbuchel H, Hendriks J, Hindricks G, Manolis AS, Oldgren J, Popescu BA, Schotten U, Van Putte B, Vardas P, Agewall S, Camm J, Baron Esquivias G, Budts W, Carerj S, Casselman F, Coca A, De Caterina R, Deftereos S, Dobrev D, Ferro JM, Filippatos G, Fitzsimons D, Gorenek B, Guenoun M, Hohnloser SH, Kolh P, Lip GY, Manolis A, McMurray J, Ponikowski P, Rosenhek R, Ruschitzka F, Savelieva I, Sharma S, Suwalski P, Tamargo JL, Taylor CJ, Van Gelder IC, Voors AA, Windecker S, Zamorano JL, Zeppenfeld K. 2016 ESC Guidelines for the management of atrial fibrillation developed in collaboration with EACTS. Europace. 2016;18:1609-78.

5. Steffel J, Verhamme P, Potpara TS, Albaladejo P, Antz M, Desteghe L, Haeusler KG, Oldgren J, Reinecke H, Roldan-Schilling V, Rowell N, Sinnaeve P, Collins R, Camm AJ, Heidbüchel H. The 2018 European Heart Rhythm Association Practical Guide on the use of non-vitamin K antagonist oral anticoagulants in patients with atrial fibrillation. Eur Heart J. 2018;39:1330-933. 
6. Proietti M, Romanazzi I, Romiti GF, Farcomeni A, Lip GYH. Real-world use of Apixaban for stroke prevention in atrial fibrillation: a systematic review and meta-analysis. Stroke. 2018;49:98-106.

7. Navarro-Almenzar B, Cerezo-Manchado JJ, CaroMartinez C, García-Candel F, Flores Blanco PJ, Ruiz GE, Andreu Cayuelas JM, Montoya FA, Cascales A, Lova Navarro A, García Alberola A, Andrés Pascual Figal D, Bailen Lorenzo JL, Manzano-Fernández S. Real-life behaviour of direct oral anticoagulants in a Spanish cohort with non-valvular atrial fibrillation: Refase Registry. Curr Med Res Opin. 2019; 35: 2035-2041

8. Hohnloser SH, Basic E, Nabauer M. Comparative risk of major bleeding with new oral anticoagulants (NOACs) and phenprocoumon in patients with atrial fibrillation: a post-marketing surveillance study. Clin Res Cardiol. 2017;106:618-28.

9. Schulman S, Kearon C, Subcommittee on Control of Anticoagulation of the Scientific, and Standardization Committee of the International Society on Thrombosis, and Haemostasis. Definition of major bleeding in clinical investigations of antihemostatic medicinal products in non-surgical patients. J Thromb Haemost. 2005;3:692-4.

10. Bundesausschuß G. Beschluss des Gemeinsamen Bundesausschusses über eine Änderung der Arzneimittel-Richtlinie (AM-RL): Anlage XII - Beschlüsse über die Nutzenbewertung von Arzneimitteln mit neuen Wirkstoffen nach § 35a SGB V Apixaban (neues Anwendungsgebiet). BAnz AT. 2013;01(08):B4.

11. Hylek EM, Evans-Molina C, Shea C, Henault LE, Regan S. Major hemorrhage and tolerability of warfarin in the first year of therapy among elderly patients with atrial fibrillation. Circulation. 2007;115:2689-96.

12. Wilke T, Groth A, Fuchs A, Pfannkuche M, Maywald U. Persistence with VKA treatment in newly treated atrial fibrillation patients: an analysis based on a large sample of 38,076 German patients. Eur J Clin Pharmacol. 2017;73:1437-47.

13. Paquette M, Riou França L, Teutsch C, Diener HC, Lu S, Dubner SJ, Ma CS, Rothman KJ, Zint K, Halperin JL, Huisman MV, Lip GYH, Nieuwlaat R. Persistence with dabigatran therapy at 2 years in patients with atrial fibrillation. J Am Coll Cardiol. 2017;70:1573-83.

14. Verdecchia P, D'Onofrio A, Russo V, Fedele F, Adamo F, Benedetti G, Ferrante F, Lodigiani C, Paciullo F, Aita A, Bartolini C, Molini MG, Di Lenarda A, Mazzone C, Scotti L, Lanati EP, Iorio A. Persistence on apixaban in atrial fibrillation patients: a retrospective multicentre study. J Cardiovasc Med (Hagerstown). 2019;20:66-73.

15. Perreault $\mathrm{S}$, de Denus $\mathrm{S}$, White-Guay B, Côté $\mathrm{R}$, Schnitzer ME, Dubé MP, Dorais M, Tardif JC. Oral anticoagulant prescription trends, profile use, and determinants of adherence in patients with atrial fibrillation. Pharmacotherapy. 2019. https://doi. org/10.1002/phar.2350.

16. Collings SL, Lefèvre C, Johnson ME, Evans D, Hack G, Stynes G, Maguire A. Oral anticoagulant persistence in patients with non-valvular atrial fibrillation: a cohort study using primary care data in Germany. PLoS ONE. 2017;12:e0185642.

17. Montalescot G, Brotons C, Cosyns B, Crijns HJ, D'Angelo A, Drouet L, Eberli F, Lane DA, Besse B, Chan A, Vicaut E, Darius H. Educational impact on apixaban adherence in atrial fibrillation (the AEGEAN STUDY): a randomized clinical trial. Am J Cardiovasc Drugs. 2019. https://doi.org/10.1007/ s40256-019-00356-2.

18. Sato T, Aizawa Y, Fuse K, Fujita S, Ikeda Y, Kitazawa $H$, Takahashi M, Okabe M. The comparison of inappropriate-low-doses use among 4 direct oral anticoagulants in patients with atrial fibrillation: from the database of a single-center registry. J Stroke Cerebrovasc Dis. 2018;27:3280-8.

19. Steinberg BA, Shrader P, Pieper K, Thomas L, Allen LA, Ansell J, Chan PS, Ezekowitz MD, Fonarow GC, Freeman JV, Gersh BJ, Kowey PR, Mahaffey KW, Naccarelli GV, Reiffel JA, Singer DE, Peterson ED, Piccini JP; Outcomes Registry for Better Informed Treatment of Atrial Fibrillation (ORBIT-AF) II Investigators. Frequency and Outcomes of Reduced Dose Non-Vitamin K Antagonist Anticoagulants: Results From ORBIT-AF II (The Outcomes Registry for Better Informed Treatment of Atrial Fibrillation II). J Am Heart Assoc. 2018 Feb 16;7(4): e007633

20. Steinberg BA, Shrader P, Thomas L, Ansell J, Fonarow GC, Gersh BJ, Kowey PR, Mahaffey KW, Naccarelli G, Reiffel J, Singer DE, Peterson ED, Piccini JP; ORBIT-AF Investigators and Patients. OffLabel Dosing of Non-Vitamin K Antagonist Oral Anticoagulants and Adverse Outcomes: The ORBITAF II Registry. J Am Coll Cardiol. 2016 Dec 20;68(24):2597-2604

21. Amarenco P, Haas S, Hess S, Kirchhof P, Lambelet M, Bach M, Turpie AGG, Camm AJ. Outcomes associated with non-recommended dosing of rivaroxaban: results from the XANTUS study. Eur Heart J Cardiovasc Pharmacother. 2019 Apr 1;5(2): 70-9.

22. Camm AJ, Amarenco P, Haas S, Hess S, Kirchhof P, Kuhls S, van Eickels M, Turpie AG. XANTUS: a realworld, prospective, observational study of patients 
treated with rivaroxaban for stroke prevention in atrial fibrillation. Eur Heart J. 2016;37(14):1145-53.

23. De Caterina R, Agnelli G, Laeis P, Unverdorben M, Rauer H, Wang CC, Nakamura M, Chiu KM, Reimitz PE, Koretsune Y, Chen C, Thee U, Kaburagi J,
Kim YH, Choi WI, Yamashita T, Cohen A, Kirchhof $P$. The global edoxaban treatment in routine cliNical prActice (ETNA) noninterventional study program: rationale and design. Clin Cardiol. 2019;42: 1147-54. 